\begin{abstract}
Introduction: Misdiagnosis in Parkinson's disease (PD) can reach 25\%. Recently, single-photon emission computer tomography (SPECT), using dopamine transporter (DAT) radioligands, has become useful to help diagnose clinically unclear cases of Parkinsonism (CUCP). Objectives: Study 1 reported the rationale of molecular imaging in CUCP. Study 2 evaluated the role of DAT neuroimaging in CUCP. Study 3 studied a sub-group of CUCP with psychogenic Parkinsonism. Study 4 investigated the relationship between DAT and depression in PD. Methods: Brain SPECT imaging was undertaken using the DAT radiotracer [99mTc]-TRODAT-1 at baseline to determine pre-synaptic dopaminergic dysfunction. Patients were followed-up, and a final clinical diagnosis was made. Results: In study 1, convincing evidence showed that molecular imaging can reduce diagnostic uncertainty in PD. In study 2, disagreement rate between SPECT imaging versus golden standard clinical diagnosis reached $20 \%$. Sensitivity and specificity (DAT scan) were, respectively, 100 and $70 \%$. However, in study 3 , two out of five subjects with psychogenic Parkinsonism had DAT densities under the cut-off suggesting a degenerative Parkinsonism. In study 4, DAT density was greater in PD patients with depression. Conclusions: This thesis confirmed the useful role of molecular imaging in CUCP, and provided in vivo information about different underlying PD-related physiopathology mechanisms.
\end{abstract}

Key words: Parkinson's disease, photon emission computer tomography, dopamine transporter, depression.

\title{
The role of transcranial Doppler in hydrocephalus (Abstract)
}

\section{O papel do Doppler transcraniano na hidrocefalia (Resumo)}

\author{
André P.C. Matta
}

Universidade Federal Fluminense (UFF), Rio de Janeiro RJ, Brazil; Hospital Universitário Antônio Pedro (2008), Niterói RJ, Brazil.

Orientador: Oswaldo J. M. Nascimento.

Correspondence: André PC Matta; Sala da Pós-graduação em Neurologia; Avenida Marquês de Paraná 303 / Prédio anexo / $4^{\circ}$ andar; $24030-211$ Niterói RJ -

Brasil; E-mail: andrepcmatta@hotmail.com

\begin{abstract}
The most usual tests for hydrocephalus diagnosis and follow-up are computed tomography (CT) and magnetic resonance imaging (MRI). Recently, there has been a growing interest as to the use of transcranial Doppler (TCD) in the indirect evaluation of intracranial pressure (ICP). This work aimed at studying the role of TCD in the evaluation of ICP in myelomeningocele and hydrocephalic patients, and also at checking whether there may be a significant difference in the pulsatility index (PI) and resistance index (RI) in the anterior cerebral artery among patients with (group B) and without (group A) ICP decompensation. The cerebral hemodynamic characteristics found by TCD were analyzed with the application of the Student's t-test. Cutoff points were defined through the "Receiver Operating Characteristic" analysis. The SPSS ${ }^{\text {TM }}$ program, version 13.0, was used for the statistical analysis. In group A, 27 patients were included -16 girls, average age $8.11( \pm 3.79)$ months. In group B, 15 children were evaluated - eight girls, average age $8.67( \pm 4.12)$ months. In group A, the average PI was $0.78( \pm 0.11)$. In group B, the average PI was $1.17( \pm 0.10)$. In group A, the average RI was $0.58( \pm 0.05)$. In group $B$, the average RI was $0.72( \pm 0.05)$. There was a statistically significant difference of $\mathrm{Pl}$ and $\mathrm{RI}$ in both groups ( $\mathrm{p}<0.0001)$. Adopting the lowest value found in group $\mathrm{B}(0.97)$ as the PI cutoff point, sensitivity between 93 and $100 \%$ and $96 \%$ specificity were found. Adopting the lowest value in group B (0.63) as the RI cutoff point, $93 \%$ sensitivity and $89 \%$ specificity were found. For those cutoff points, the PI positive predictive value was $96.3 \%$, and the negative predictive value was $100 \%$. The RI positive predictive value was $88.9 \%$, and the negative predictive value was $93.3 \%$. One can say that TCD plays an important role in the evaluation of ICP in children with myelomeningocele and hydrocephalus, since there was a significant difference of the PI and RI values in the anterior cerebral artery, within patient groups with and without decompensation. Besides, it became very clear that the method's sensitivity, specificity, as well as its predictive values, are high.
\end{abstract}

Key words: ultrasonography, Doppler, transcranial, hydrocephalus. 